\title{
OPTIMISM AND RESILIENCE AMONG UNIVERSITY STUDENTS
}

\author{
Rocío Gómez-Molinero \\ Emotional Intelligence Laboratory University of Cádiz (Cádiz, Spain) \\ rocio.gomezmolinero@alum.uca.es \\ Antonio Zayas \\ Emotional Intelligence Laboratory University of Cádiz (Cádiz, Spain) \\ Research Institute for Sustainable Social Development (INDESS, Jerez de la Frontera, Cádiz, Spain) \\ Paula Ruíz-González \\ Emotional Intelligence Laboratory University of Cádiz (Cádiz, Spain) \\ Research Institute for Sustainable Social Development (INDESS, Jerez de la Frontera, Cádiz, Spain) \\ Rocío Guil \\ Emotional Intelligence Laboratory University of Cádiz (Cádiz, Spain) \\ Research Institute for Sustainable Social Development (INDESS, Jerez de la Frontera, Cádiz, Spain)
}

Fecha de Recepción: 24 Febrero 2018

Fecha de Admisión: 10 Abril 2018

\begin{abstract}
University life is full of stressful stimuli that can contribute to psychological distress and lower performance levels. Despite academic demands, university students also face new stressors, such as different social networks, financial changes, and adaptation to new family and social roles that may have a negative impact on their mental health (Pidgeon \& Pickett, 2017). In this sense, resilience literature has gained acceptance explaining how some students successfully adapt to university life while others find great challenges. Since resilience has been defined as the ability to successfully adapt in the face of stress and adversity, it is important to determine what psychological factors contribute enhancing this resilience levels. One of the factors related to life adaptation is optimism, understood as the general expectancy of obtaining positive outcomes in the future (Scheier \& Carver, 1985). Hence, the aim of this study is to study the relationship between optimism and resilience among a sample of university students in Spain.

The sample was comprised of 132 students from the University of Cádiz (Spain). Participants were selected by quota sampling from first to last year of studies. The majority of students $(72.5 \%)$ were female and average age was 21.71 (range $=18-48, S D=3.75$ ). Participants completed the Wagnild and Young Resilience Scale (Spanish version adapted by Novella, 2002) and Life Orientation Test (LOT-R Spanish version adapted by Ferrando, Chico \& Tous).
\end{abstract}




\section{OPTIMISM AND RESILIENCE AMONG UNIVERSITY STUDENTS}

We performed hierarchical multiple regression analysis and obtained that optimism explained $25 \%$ of resilience among university students $\left(R^{2}=.25, \beta=.49\right)$. No gender and age differences were observed. Thus, identifying the factors that influence students' adjustment to university life can improve the targeting of interventions to improve university academic performance. Moreover, this research could contribute helping students to successfully face this life transition, increasing their well-being and life satisfaction levels and decreasing university absenteeism.

Keywords: resilience; optimism; transition to university; academic performance

\section{INTRODUCTION}

Transition to university is a problematic stage that many young adults face. In fact, as literature has indicated, transitions are a source of stress where individuals leave the familiar network behind, entering into an unfamiliar territory (Latham \& Green, 1997). Besides, the academic pressure university students are exposed to, can have a negative effect on their mental health (Pidgeon et al., 2014). Indeed, mental illness rates are above general population rates when undergraduates get to their second year of university (Macaskill, 2013). In addition to the demands in the academic field, university students also experience other stressors such as financial burden and housing changes, the formation of new social networks as well as adaptation to new social and family roles (Tavolacci, 2011, Pidgeon and Pickett, 2017). Therefore, it is important to understand what factors may promote an adequate adjustment, since an adequate adaptation into the new university context increases the permanence rate in universities (Pigeon and Pickett, 2017), as well as academic success and higher well-being levels. In this sense, resilience research has been gaining acceptance as a framework explaining why some students adapt successfully to university life while others face great challenges (Hiester, Nordstrom, and Swenson, 2009).

Defining resilience has been a challenge for academics since this term has been used in a wide variety of contexts, including organizational, educational, community, sports, military, and clinical. Moreover, this concept was first used in the field of physics to define the properties of elastic objects that were able to recover their original shape after being bench or stretched (Dyer and McGuinness, 1996). In general terms, all resilience definitions are divided into two groups: resilience as a personality trait and resilience as a developmental factor (Mestre et al, 2017). The first group of definitions states that resilience is a fix and stable over time implying that this term is unable to explain the adaptation of individuals and the environment (Lee et al., 2012). Conversely, the second group of definitions states that resilience is a dynamic process, changeable over time and influenced by the environment (Lee et al. 2013). We agree with this second group of definitions understanding that resilience is a process of adapting well in the face of adversity (American Psychological Association, 2017). In this sense, while some students are more resilient, others may face many more difficulties facing their life stage adversities, resulting in lower academic performance and in some cases in university withdrawal.

Literature has highlighted the role of resilience as a protective factor. According to Rutter (1990), a resource, internal and external, acts as a protective factor if it moderates risk. Campbell-Sills and colleagues (2006) found that individuals who are highly resilient engage more often in adaptive coping skills and convert stressful situations into opportunities for learning and development. Besides, in a sample of college students, it was found that students high on resilience face stressful situation using problem-solving coping strategies (Kariv \& Heiman, 2005) what lead to better academically compared to students who used emotion-focused coping strategies (Struthers et al., 2000). In a more recent study, Rahat and IIhan (2016) have found that college students with high levels of resilience displayed better adjustment to university. Therefore, a student's levels of resilience are related to effective adaptive resources to academic stress. Hence, resilience, construct framed in the 
positive psychology field, can be understood as a protective factor since it prevents students from maladaptive strategies reducing, in turn, academic stress levels.

Another protective resource that has been well studied is optimism. Optimism refers to the general expectancy that one will experience good outcomes in the future (Scheier \& Carver, 1985). According to literature, optimism is composed of two important elements: "learned optimism" (Peterson \& Seligman, 1984) and "dispositional optimism" (Scheier \& Carver, 1985). Learned optimism is as a personal trait and optimistic individuals use an adaptive attributional style in order to explain adverse situations. In turn, dispositional optimism refers to a general belief that good things will happen rather than bad things in the future. Hence, optimism, understood as a personality trait reflects good expectations for the future.

Literature has highlighted the benefits that optimism have on physical and psychosocial wellbeing, i. e. reducing depressive symptoms and stress impact, enhancing self-esteem, forming and maintaining relationships, and favoring adjustment to university life (Ferguson \& Goodwin, 2010; Hatchett \& Park, 2004; Krypel \& Henderson-King, 2010; Puskar et al., 2010). In a recent study, it was found that optimistic students were more academically engage that non-optimistic ones (Ouweneel et al., 2011).

Research on physical health also supports the positive effects of optimism. Aspinwall and Taylor (1992) found that optimism was indirectly associated with physical illness through better adaptation to stressors. This is in line with literature suggesting optimism might reduce the negative effect that stress has on the immune response (Segerstrom, 1998). Besides, it has been found that optimistic college students reported fewer minor illness symptoms during stressful times than did pessimistic students (Scheier \& Carver, 1985).

Having good expectations about the future also play an important role in adaptation to traumatic or stressful situations. According to Snyder, Lopez, and Pedrotti (2002), optimistic people display higher levels of resilience when facing challenging situations. Besides, optimism has been identified as the most significant adolescent cognitive factor diminishing the effects of life stressors (TusaieMumford, 2001). In general, it seems that the concept of resilience reflects a desire for great optimism under adversity (Rutter, 2006); in other words, optimism accompanies resilience in stressful situations (Carver, Scheier, and Segerstrom, 2010). Besides, it has been found a direct relationship between optimism and psychological resilience with symptoms of depression (Kapikiran, 2012).

Taking into consideration that transition to university appears as a major disruptive stage where young adults have to face numerous stressful situations, it is important to understand the role that these protective factors have in order to successfully manage stressful circumstances. Besides, due to the lack of studies relating resilience and good expectancies about the future (optimism) at university stage, the goal of this study is to explore the relationship between these two variables in a university students sample from Spain.

\section{METHODS}

\section{Participants and procedure}

The sample is composed of 132 students from the University of Cádiz (Spain) from first to last year of studies. Participants were selected by quota sampling from different degrees. The majority of students $(72.5 \%)$ were female and average age was 21.71 (range $=18-48, S D=3.75$ ). Participants were given a questionnaire with all the scales presented at the same time. The students had no time limitation and the questionnaires were completed during their leisure time. Participation was anonymous and voluntary. Before completing the questionnaire, participants had to sign an informed consent. 


\section{Instruments}

Resilience, Wagnild y Young Resilience Scale (1993), Spanish version adapted by Novella (2002). This instrument assesses the ability of students to face adverse situations. The scale is composed of 25 items, in a 7-point Likert scale, ranging from 1 (totally disagree) to 7 (totally agree). All items are positively scored. The possible total scores range from 25 to 175 with higher scores reflecting higher resilience. It includes a global resilience measure and six dimensions: meaningfulness, people's ability to understand the meaning of life and their contributions; existential aloneness, feeling of freedom and sense of uniqueness; self-reliance, ability to believe in oneself and one's abilities; equanimity, referrers to the ability of the person to show a balanced perspective concerning their own life and experiences, take things slowly, and moderating their attitudes to an adverse event; perseverance, persistence in the face of adversity or a threatening situation, together with a strong desire for achievement, and self-discipline. For the purpose of this study, only global resilience will be included. Example items were "Cronbach obtained for this research was .89.

Optimism, Life Orientation Test (LOT-R) (Scheier, Carver \& Bridges, 1994), Spanish version adapted by Otero et al. (1998). This scale assesses the tendency of the individual to see and judge things in their most positive or most favorable aspect. This instrument consists of 10 items that are scored following a 5-point Likert scale ranging from 1 (maximum disagreement) to 5 (maximum agreement). Example items were Cronbach obtained for this research was .82.

\section{RESULTS}

Descriptive statistics, correlations (Pearson's r), and Cronbach's alphas were calculated for each measure of the sample (Table 1). As we can see in Table 1, students showed medium levels of resilience and medium-high levels of optimism. Age and resilience significantly correlate with optimism levels and sex did not significantly affect any variable. These preliminary results suggested levels of dispositional optimism are higher as age increases for this sample. Moreover, undergraduates with higher levels of optimism also displayed high levels of resilience.

Table1. Descriptive statistics, correlations, and Cronbach's alphas

\begin{tabular}{lcccccccc}
\hline & Mean & $S D$ & Min-Max & Sex & Age & OPT. & RES. & $\alpha$ \\
\hline Sex & & & & - & & & \\
Age & 21.71 & 3.75 & $18-48$ &, 15 & - & & & \\
OPT. & 3.47 & .70 & $1.83-5$ &, 09 &, $201^{*}$ & - & .82 \\
RES. & 3.24 & .71 & $3.24-7.96$ &, 03 &, 11 &, $48^{* *}$ & - & .89 \\
\hline
\end{tabular}

NOTE. OPT. $=$ Optimism, RES. $=$ Resilience

$* \mathrm{p}<.05, * * \mathrm{p}<.01$

In order to determine if dispositional optimism and students age predicted total resilience, hierarchical linear regression analysis was performed (Table 2). Total resilience was included as the dependent variable, dispositional optimism as the independent variable, and age and sex as control variables. As shown in Table 2, sex and age, included in Step 1, did not significantly affect global resilience levels, explaining only $2 \%(\mathrm{R} 2=.02)$ of resilience variance, resulting this model not statistically significant. In Step 2, and after including optimism variable, the model explained $25 \%$ (R2 $=.25$ ) of total resilience variance for this sample. Thus, control variables (sex and age) did not affect resilience. In turn, optimism statistically predicted the ability to adapt well in the face of adversity ( $\beta$ $\left.=.49^{\star \star \star}\right)$. 
Table2. Summary of Hierarchical Regression Analysis for Variables Predicting Total Resilience

\begin{tabular}{|c|c|c|c|c|}
\hline Variable/Predictor Variable & $\mathrm{R}$ & $\mathrm{R}^{2}$ & $F$ for change in $R^{2}$ & $\beta$ \\
\hline \multicolumn{5}{|l|}{ RES. } \\
\hline Step 1 & & .02 & 1.10 & \\
\hline $\begin{array}{l}\text { Sex } \\
\text { Age }\end{array}$ & & & & $\begin{array}{r}.13 \\
-.02\end{array}$ \\
\hline Step 2 & & .25 & & \\
\hline $\begin{array}{l}\text { Sex } \\
\text { Age } \\
\text { OPT. }\end{array}$ & & & $38.66^{* * *}$ & $\begin{array}{c}.03 \\
-.06 \\
.49^{* * *}\end{array}$ \\
\hline
\end{tabular}

NOTE. OPT. $=$ Optimism, RES. $=$ Resilience

$* \mathrm{p}<.05, * * \mathrm{p}<.01$

\section{DISCUSSION}

This research aimed to determine the role of positive expectations about the future (optimism) on resilience, among a sample of university students from Spain. Literature up to date has been focused on the relationship between resilience and optimism in other developmental stages, however, little is known about the relationship between optimism and resilience during the transition to university.

The results of the study indicated that optimism significantly predicted resilience levels among university students. That means that students who have good expectations about their future will face adversity in a more adaptive way. Besides, optimistic undergraduates will also show a better adaptation to the new stressors they will encounter during this transition stage, such as financial burden and academic demands.

Our results are in line with existent literature supporting our view that trait optimism is a factor contributing to resilience (Tusaie-Mumford, 2001: Snyder, Lopez, and Pedrotti, 2002). According to Yu and Zhang (2007) optimism reflects individuals' positive attitudes towards adverse circumstances establishing that optimism is one of the most important aspects of resilience development. Moreover, previous studies have indicated that there appears to be a positive relationship between optimism and well-being (Scheier and Carver, 1985). In this line of reasoning, it is important to enhance students' optimism in order to increase their chances to face challenges in more adaptive manner.

Results of this research appear to confirm that optimism acts as a protective factor enhancing resilience levels and helping to reduce psychological distress caused by this life transition. In this sense, future research should investigate the effectiveness of interventions aimed to enhance students' optimism, in order to improve university resilience. In this sense, students able to deal with stressors could achieve better academic performance levels and might decrease anxiety and depression levels. Taking into consideration that mental illness rates of university students surpass general population ratio at second year of university (Macaskill, 2013), it will be interesting to test if this mental problems abates after enhancing their future expectations.

Finally, this research could serve as a guide to develop initial courses to help students to successfully face this life transition, increasing their well-being and life satisfaction levels and decreasing university absenteeism. 


\section{BIBLIOGRAPHY}

American Psychological Association (2017). The Road to Resilience. Available online at: http://www.apa.org/helpcenter/road-resilience.aspx

Aspinwall, L. G., \& Taylor, S. E. (1992). Modeling cognitive adaptation: A longitudinal investigation of the impact of individual differences and coping on college adjustment and performance. Journal of personality and social psychology, 63(6), 989.

Campbell-Sills, L., Barlow, D. H., Brown, T. A., \& Hofmann, S. G. (2006). Effects of suppression and acceptance on emotional responses of individuals with anxiety and mood disorders. Behaviour research and therapy, 44(9), 1251-1263.

Dyer, J. G., \& McGuinness, T. M. (1996). Resilience: Analysis of the concept. Archives of psychiatric nursing, 10(5), 276-282.

Ferguson, S. J., \& Goodwin, A. D. (2010). Optimism and well-being in older adults: The mediating role of social support and perceived control. The International Journal of Aging and Human Development, 71(1), 43-68.

Ferrando, P. J., Chico, E., \& Tous, J. M. (2002). Propiedades psicométricas del test de optimismo Life Orientation Test. Psicothema, 14(3).

Hatchett, G. T., \& Park, H. L. (2004). Relationships among optimism, coping styles, psychopathology, and counseling outcome. Personality and Individual Differences, 36(8), 1755-1769.

Hiester, M., Nordstrom, A., \& Swenson, L. M. (2009). Stability and change in parental attachment and adjustment outcomes during the first semester transition to college life. Journal of College Student Development, 50(5), 521-538.

Kapikiran, N. A. (2012). Positive and negative affectivity as mediator and moderator of the relationship between optimism and life satisfaction in Turkish university students. Social Indicators Research, 106(2), 333-345.

Kapikiran, S., \& Acun-Kapikiran, N. (2016). Optimism and Psychological Resilience in Relation to Depressive Symptoms in University Students: Examining the Mediating Role of SelfEsteem. Educational Sciences: Theory and Practice, 16(6), 2087-2110.

Kariv, D., \& Heiman, T. (2005). Task-oriented versus emotion-oriented coping strategies: The case of college students. College Student Journal, 39(1), 72-85.

Karmalkar, S. J., \& Vaidya, A. (2018). Resilience of rural-to-urban migrant adolescents: The role of gender and socio-economic status. Indian Journal of Health and Wellbeing, 9(1), 101-105.

Krypel, M. N., \& Henderson-King, D. (2010). Stress, coping styles, and optimism: are they related to meaning of education in students' lives?. Social Psychology of Education, 13(3), 409-424.

Latham, G., \& Green, P. (1997). The journey to university: A study of „the first year experience . Retrieved, 20 December, 2010 from http://ultibase.rmit.edu.au/Ariticles/dec97/greenlath1.htm.

Lee J. H., Nam S. K., Kim A.-R., Kim B., Lee M. Y., Lee S. M. (2013). Resilience: a meta-analytic approach. J. Couns. Dev. 91, 269-279

Lee, T. H., Choi, J. S., \& Cho, Y. S. (2012). Context modulation of facial emotion perception differed by individual difference. PLoS One, 7(3).

Macaskill A., (2013). The mental health of university students in the United Kingdom. Br J Guidance Couns, 41, 426-41

Mestre, J. M., Núñez-Lozano, J. M., Gómez-Molinero, R., Zayas, A., \& Guil, R. (2017). Emotion regulation ability and resilience in a sample of adolescents from a suburban area. Frontiers in psychology, 8.

Novella, A. (2002). Incremento de la resiliencia luego de la aplicación de un programa de psicoterapia breve en madres adolescentes. Tesis para optar el grado académico de Magíster en Psicología Clínica y de la Salud. Lima: Universidad Nacional Mayor de San Marcos. 
Otero-López, J. M., Luengo, A., Romero, E., Gómez, J. A., \& Castro, C. (1998). Psicología de personalidad. Manual de prácticas. Barcelona: Ariel Practicum.

Ouweneel, E., Le Blanc, P. M., \& Schaufeli, W. B. (2011). Flourishing students: A longitudinal study on positive emotions, personal resources, and study engagement. The journal of positive psychology, 6(2), 142-153.

Peterson, C., \& Seligman, M. E. (1984). Causal explanations as a risk factor for depression: Theory and evidence. Psychological review, 91(3), 347.

Pidgeon, A. M., \& Pickett, L. (2017). Examining the Differences Between University Students' Levels of Resilience on Mindfulness, Psychological Distress and Coping Strategies. European Scientific Journal, ESJ, 13(12).

Pidgeon, A. M., Rowe, N. F., Stapleton, P., Magyar, H. B., \& Lo, B. C. (2014). Examining characteristics of resilience among University students: An international study. Open journal of social sciences, 2(11), 14.

Puskar, K. R., Marie Bernardo, L., Ren, D., Haley, T. M., Hetager Tark, K., Switala, J., \& Siemon, L. (2010). Self-esteem and optimism in rural youth: Gender differences. Contemporary Nurse, 34(2), 190-198.

Rahat, E., \& Ihan, T. (2016). Coping Styles, Social Support, Relational Self-Construal, and Resilience in Predicting Students' Adjustment to University Life. Educational Sciences: Theory and Practice, 16(1), 187-208.

Richardson, G.E., et al., The resiliency model. Health Education, 21(6), 33-39, 1990.

Rutter, M. (1990). Commentary: Some focus and process considerations regarding effects of parental depression on children. Developmental psychology, 26(1), 60.

Rutter, M. (2006). Implications of resilience concepts for scientific understanding. Annals of the New York Academy of Sciences, 1094(1), 1-12.

Scheier, M. F., \& Carver, C. S. (1985). Optimism, coping, and health: assessment and implications of generalized outcome expectancies. Health psychology, 4(3), 219.

Segerstrom, P. S. (1998). Endogenous growth without scale effects. American Economic Review, 1290-1310.

Segerstrom, S. C., Taylor, S. E., Kemeny, M. E., \& Fahey, J. L. (1998). Optimism is associated with mood, coping, and immune change in response to stress. Journal of personality and social psychology, 74(6), 1646.

Snyder, C. R., Lopez, S. J., \& Pedrotti, J. T. (2010). Positive psychology: The scientific and practical explorations of human strengths. Sage Publications.

Struthers, C. W., Perry, R. P., \& Menec, V. H. (2000). An examination of the relationship among academic stress, coping, motivation, and performance in college. Research in higher education, 41(5), 581-592.

Tavolacci M. P., Ladner J., Grigioni S., Richard L., Villet H. Dechelotte P. Prevalence and association of perceived stress, substance use and behavioral addictions: A cross-sectional study among university students in France, 2009-2011. BMC Public Health. 2013;13:724

Tusaie-Mumford, K. (2001). Psychosocial resilience in rural adolescents: Optimism, perceived social support and gender differences (Doctoral dissertation, University of Pittsburgh).

Wagnild G, Young H. Development and psychometric evaluation of the resilience scale. J Nurs Meas 1993;1:165-7. 
